NOTE

\title{
Rediscovery of the Australian strain of infectious hypodermal and haematopoietic necrosis virus
}

\author{
Kjersti Krabsetsve, Bradford R. Cullen, Leigh Owens*
}

Microbiology and Immunology, James Cook University, Townsville 4811, Australia

\begin{abstract}
In this study we rediscovered and verified the presence of an infectious hypodermal and haematopoietic necrosis virus (IHHNV) strain amongst cultured penaeid prawns Penaeus monodon from 1993 in Australia on the basis of a PCR analysis with IHHNV specific primers and sequencing of the resulting amplicons. A total of 7 previously published diagnostic primers specific to IHHNV were tested against Australian penaeid prawns and only 1 elicited a positive IHHNV PCR result with 16 out of 20 Australian P. monodon samples examined. In comparison, all 7 primers produced IHHNVpositive amplicons from the New Caledonian control samples. Analysis and comparison of the $392 \mathrm{bp}$ fragment derived from the Australian IHHNV strain (AY590120) with other geographical isolates revealed that the Madagascar isolate shared the highest nucleotide similarity $(96.2 \%)$ and the Hawaiian and New Caledonian strain the highest nucleotide divergence (90.1 and $90.3 \%$ respectively). The high nucleotide variation observed between the Australian and Hawaiian strains provides an explanation for the lack of IHHNV detection amongst Australian prawns with published IHHNV PCRs and commercially available gene probes as they are primarily designed on the basis of the Hawaiian strain (AF218266). Results indicated that IHHNV has been present in Australia for a long (geological and contemporary) time and that the virus is endemic in penaeid prawns in the Australian environment.
\end{abstract}

KEY WORDS: IHHNV $\cdot$ Penaeus monodon $\cdot$ Australia $\cdot$ Virus $\cdot$ Prawn $\cdot$ PCR

\section{INTRODUCTION}

The parvovirus infectious hypodermal haematopoietic necrosis virus (IHHNV) causes acute disease in juvenile Penaeus stylirostris (Bonami et al. 1990). Runt deformity syndrome (RDS) has been linked to chronic IHHNV in Penaeus vannamei (Kalagayan et al. 1991, Browdy et al. 1993) and Penaeus monodon (Primavera \& Quinitio 2000). As such, OIE (2003a) has it listed in the Aquatic Animal Health Code.

Evidence for IHHNV existing in Australian penaeids has been accruing for sometime. Owens (1987) presented a paper that demonstrated histological and epidemiological evidence for the presence of IHHNV in prawns in northern Australia. Subsequently, further evidence was presented that in particular Penaeus merguiensis, P. monodon, and possibly Metapenaeus ensis all contained Cowdry type A inclusions (CAIs) typical of IHHNV (Owens \& Hall-Mendelin 1990).

In 1991, a full epizootic of IHHNV was detected in hybrid prawns (Penaeus esculentus crossed with $P$. monodon) in a research facility in northern Queensland, with mortalities approaching $100 \%$ before the last few animals were sacrificed for histological examination (Owens et al. 1992). Microscopical examination again showed CAIs widespread through almost all tissues apart from the hepatopancreatic cells themselves and the midgut cells. In particular, the lymphoid organ had almost every single cell showing CAIs. Electron microscopy allowed visualisation of 
non-enveloped viral particles between 18 and $20 \mathrm{~nm}$ flowing away from the nucleus in the cytoplasm, typical of IHHNV. Interestingly, an ELISA run on this material showed intensities of 38 and $71 \%$ compared with American IHHNV (Owens et al. 1992). Use of the BS4.5 DNA gene probe for IHHNV failed to react with Australian material even though the positive control tissue reacted (Lightner 1996). A view was forming that Australia had a strain of IHHNV not identical to the widespread IHHNV strain of the Americas (OIE 2003b).

Recently, the issue of live viruses being spread by commodity prawns for human consumption has become more prominent. Australia imports large amounts of prawns from Thailand, India and New Caledonia and exports to Japan and the USA in particular. Many countries, including Australia, are redefining their exotic and endemic disease status. Australia has a virus that presents like IHHNV in certain circumstances but appears to be different from classical IHHNV. The real status of Australian IHHNV has to be clarified to have a rational debate and a coherent policy on commodity prawns. This study was an attempt to better understand the nature of Australian IHHNV.

\section{MATERIALS AND METHODS}

Prawn samples. Previous investigations of IHHNV in populations of New Caledonian Penaeus stylirostris demonstrated that up to $99 \%$ of moribund prawns were infected, but generally at a low level of infection (Costa et al. 1998). Initial studies were therefore conducted on 20 frozen P. stylirostris purchased in 2002 from a seafood vendor in Canberra, Australia, and were transported on ice to James Cook University. These prawns originated from New Caledonia and were used in order to assess previously published diagnostic primers specific to IHHNV. The P. stylirostris samples also served as positive controls in subsequent PCRs on $P$. monodon.

Australian samples consisted of 20 wild-caught, adult broodstock Penaeus monodon, which had been kept frozen at James Cook University since 1993. The samples originated from a research institute in northern Queensland, Australia, and were animals used in a previous study (Fraser \& Owens 1996).

Nucleic acid extraction. Total DNA was extracted from approximately $50 \mathrm{mg}$ of pleopod tissue using the High Pure PCR Template Preparation Kit (Roche Diagnostics) according to the manufacturer's protocol. The quality of the extracted DNA was assessed using PCR amplification based on the 18S rRNA sequence of decapods. Primers 143F (5'-TGC-CTT-ATC-AGC-
TNT-CGA-TTG-TAG-3') and 145R (5'-TTC-AGNTTT-GCA-ACC-ATA-CTT-CCC-3') were used, yielding an 848 bp product (Lo et al. 1996).

PCR. Prawns from New Caledonia and Australia were initially screened for IHHNV infection through PCR with primers targeting the non-structural protein 1 (NS1) region of the IHHNV genome (Shike et al. 2000, Tang \& Lightner 2002). Primers IHHNV392F and IHHNV392R yielding a 392 bp product were used (Tang et al. 2000). The reaction mixture contained $200 \mu \mathrm{M}$ each dNTP, $0.3 \mathrm{mM}$ each primer, $2 \mathrm{mM} \mathrm{MgCl}_{2}$, PCR buffer (100 mM Tris-HCl, $200 \mathrm{mM}\left(\mathrm{NH}_{4}\right)_{2} \mathrm{SO}_{4}$, $0.1 \%$ Tween 20, pH 8.8), 1 U Taq polymerase (MBI Fermentas, Progen), $1 \mu$ l extracted sample template and sterile distilled water to $50 \mu$ total volume. Amplification consisted of an initial denaturation at $94^{\circ} \mathrm{C}$ for $4 \mathrm{~min}$, followed by 35 cycles of denaturation at $94^{\circ} \mathrm{C}$ for $30 \mathrm{~s}$, primer annealing at $55^{\circ} \mathrm{C}$ for $30 \mathrm{~s}$ and extension at $72^{\circ} \mathrm{C}$ for $1 \mathrm{~min}$, and a final extension at $72^{\circ} \mathrm{C}$ for $7 \mathrm{~min}$. Amplified products were visualized using electrophoresis with agarose gels stained with ethidium bromide.

Australian Penaeus monodon samples which were positive for the above screening PCR were also tested using 6 additional previously published IHHNV specific primers (Table 1). One or 2 New Caledonian $P$. stylirostris samples were included as positive controls. Collectively, the primers could theoretically amplify sequences covering nearly $80 \%$ of the IHHNV genome (Fig. 1). The PCR methods used followed those indicated in the respective published papers, except that MBI Fermentas Taq polymerase was used in all cases. Primer nucleotide positions indicated in Table 1 are based on the IHHNV total genomic sequence at GenBank (AF218266).

Cloning and sequencing. To verify the identity of the positive $392 \mathrm{bp}$ amplicon from the PCR, and to further investigate the IHHNV strains, a few selected amplicons from both New Caledonian and Australian prawn samples were cloned and sequenced. The PCR products were initially purified with the QIAquick PCR Purification Kit (QIAGEN) and cloned using the pGEM T-Easy Vector system (Promega) according to the manufacturers' protocols. At least 3 recombinant plasmids IHHNV DNA were purified using Wizard Plus SV minipreps (Promega) and analysed through PCR with primers IHHNV392F and IHHNV392R (Table 1). Positive clones from the PCR were sequenced using M13 universal primers (Promega) and a DYEnamic ET Dye Terminator Kit (Amersham Biosciences). Reaction products were analysed with a MegaBACE Sequence Analyser (Amersham BioSciences) at the Advanced Analytical Center at James Cook University. At least 4 fully overlapping forward and reverse chromatograms 
Table 1. Overview of the primers used for PCR detection of IHHNV in Australian Penaeus monodon and New Caledonian P. stylirostris

\begin{tabular}{|c|c|c|c|c|}
\hline Primer name & Primer sequence & Product length & Nucleotide position & Source \\
\hline IHHNV392F & 5'-GGGCGAACCAGAATCACTTA-3' & $392 \mathrm{bp}$ & $845-1236$ & Tang et al. (2000) \\
\hline $\begin{array}{l}77012 \mathrm{~F} \\
77353 \mathrm{R}\end{array}$ & $\begin{array}{l}\text { 5'-ATCGGTGCACTACTCGGA-3' } \\
\text { 5'-TCGTACTGGCTGTTCATC-3' }\end{array}$ & $356 \mathrm{bp}$ & $2310-2665$ & OIE (2000) \\
\hline $\begin{array}{l}389 \mathrm{~F} \\
389 \mathrm{R}\end{array}$ & $\begin{array}{l}\text { 5'-CGGAACACAACCCGACTTTA-3' } \\
\text { 5'-GGCCAAGACCAAAATACGAA-3' }\end{array}$ & $389 \mathrm{bp}$ & $1400-1788$ & OIE (2003b) \\
\hline $\begin{array}{l}\text { IHHNVF } \\
\text { IHHNVR1 }\end{array}$ & $\begin{array}{l}\text { 5'-ATGTGCGCCGATTCAACAAG-3' } \\
\text { 5'-CTAAGTGACGGCGGACAATA-3' }\end{array}$ & $1.2 \mathrm{~kb}$ & $2758-4001$ & Tang \& Lightner (2002) \\
\hline $\begin{array}{l}77012 \mathrm{~F} \\
2553 \mathrm{R}\end{array}$ & $\begin{array}{l}\text { 5'-ATCGGTGCACTACTGGGA-3' } \\
\text { 5'-CGGACAATATCCCTGACT-3' }\end{array}$ & $1.681 \mathrm{~kb}$ & $2310-3990$ & Nunan et al. (2000) \\
\hline $\begin{array}{l}\text { IHHNV721F } \\
\text { IHHNV2860R }\end{array}$ & $\begin{array}{l}\text { 5'-TCTACTGCCTCTGCAACGAG-3' } \\
\text { 5'-GTGGGTCTGGTCCACTTGAT-3' }\end{array}$ & $2.0 \mathrm{~kb}$ & $721-2860$ & Tang \& Lightner (2002) \\
\hline $\begin{array}{l}\text { IHHNV3065F } \\
\text { IHHNV3056R }\end{array}$ & $\begin{array}{l}\text { 5'-GACGACGAAGAATGGACAGA-3' } \\
\text { 5'-TGCCTGGGTAGCTGGTATGTATA-3' }\end{array}$ & $3.0 \mathrm{~kb}$ & $792-3856$ & Tang et al. (2003) \\
\hline
\end{tabular}

were compared for each clone, aligned and analysed using Sequencher ${ }^{\mathrm{TM}}$ software (Gene Codes Corporation).

Sequence analysis. Sequences derived from New Caledonian (AY590121) and Australian (AY590120) prawns were compared with IHHNV sequences from other geographical areas using BLAST searches, ClustalX Multiple Sequence Alignment Program version 1.8 (National Center for Biotechnology Information) and GeneDoc Multiple Sequence Alignment Editor and Shading Utility Version 2.6.002 (Pittsburgh Supercomputing Centre).

\section{RESULTS}

PCR

Of the 20 New Caledonian Penaeus stylirostris samples examined, 15 showed amplification with the decapod DNA quality validation PCR, and were used for subsequent testing with the IHHNV392F/R screening PCR. Results from gel electrophoresis showed that 14 of the 15 New Caledonian prawns were IHHNV-PCR positive, indicated by the presence of a $392 \mathrm{bp}$ band. After testing with the decapod PCR, all 20 Aus-

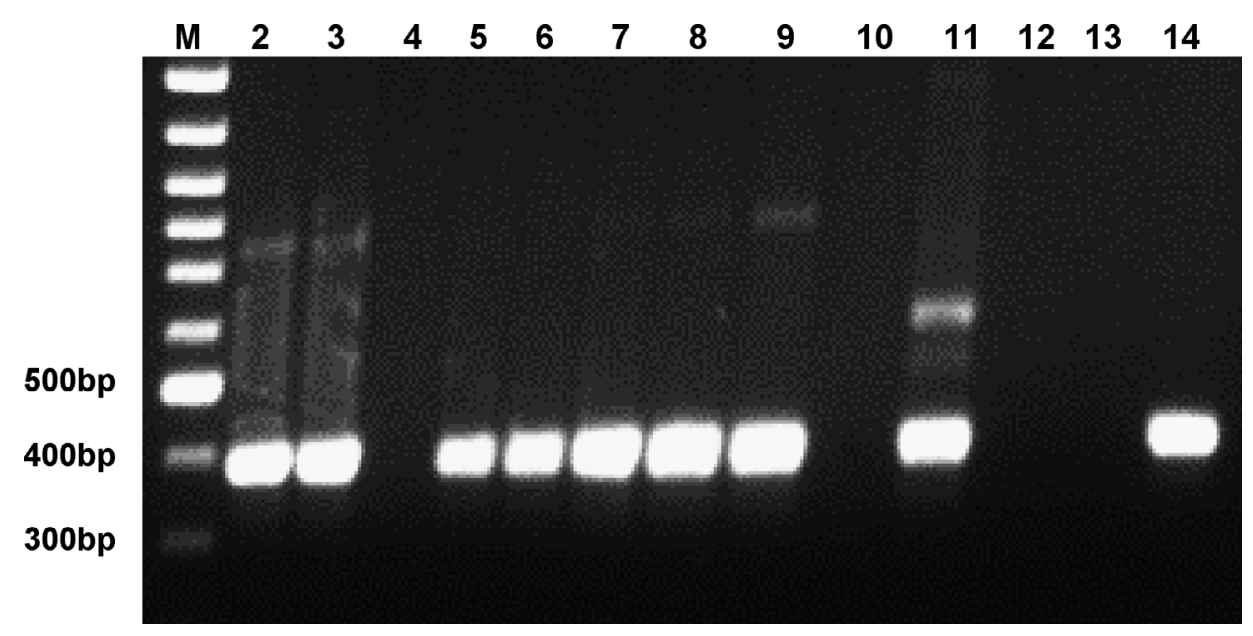

Fig. 1. PCR amplicons using primers IHHNV392F/R (392 bp expected product) with DNA extracted from pleopods of Australian prawns Penaeus monodon. Lane M: molecular weight marker (100 bp GeneRuler ${ }^{\mathrm{TM}}$, MBI Fermentas); Lanes 2-11: P. monodon pleopod samples; Lane 12: DNA extraction on sterile $\mathrm{dH}_{2} \mathrm{O}$ (negative control); Lane 13: no template (negative control); Lane 14: IHHNV from New Caledonian P. stylirostris (positive control) 

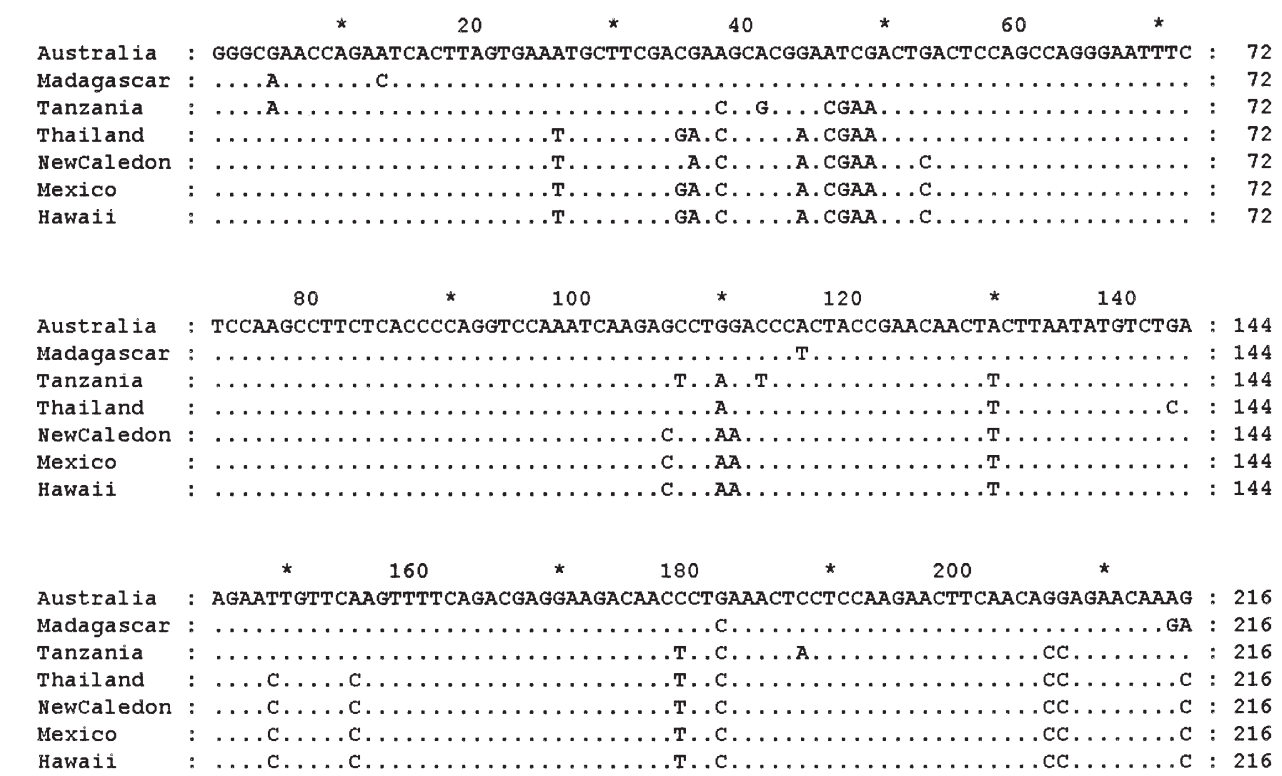

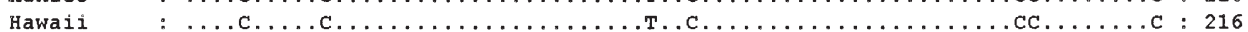
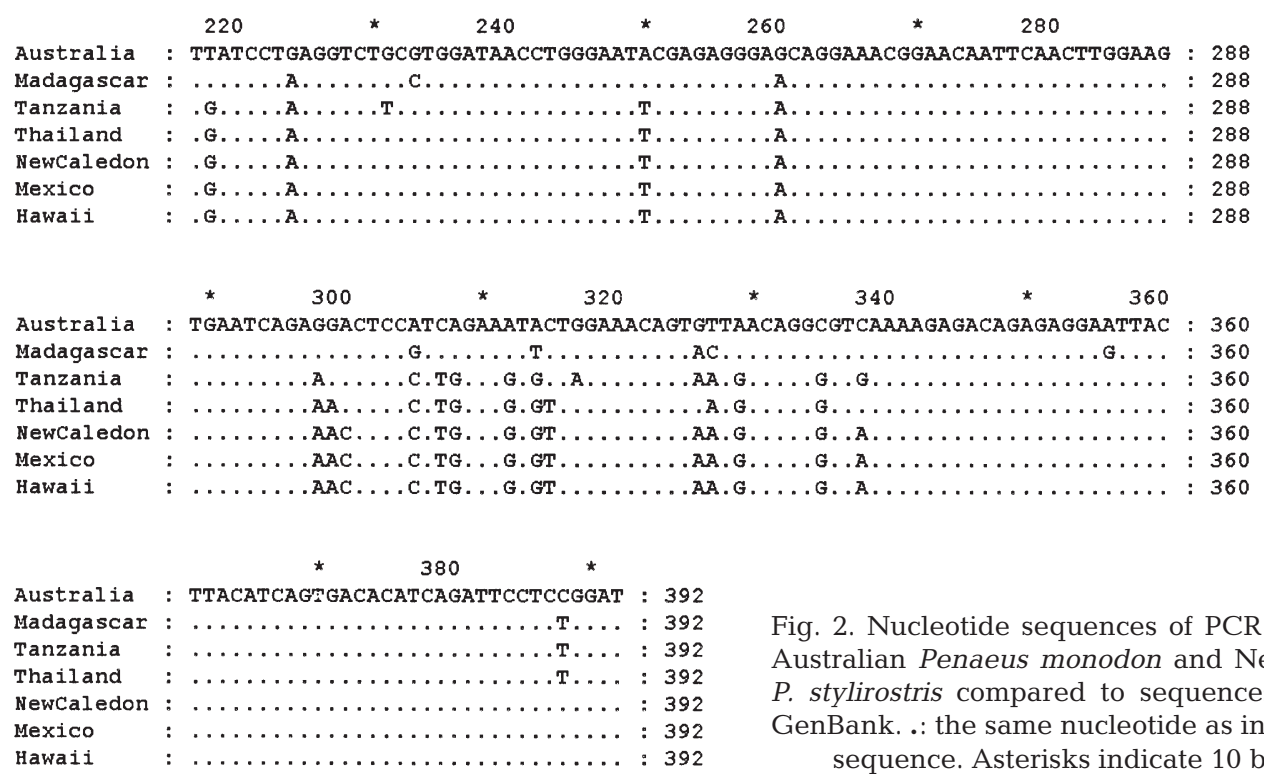

Fig. 2. Nucleotide sequences of PCR products from Australian Penaeus monodon and New Caledonian $P$. stylirostris compared to sequences submitted to GenBank. .: the same nucleotide as in the Australian sequence. Asterisks indicate $10 \mathrm{bp}$ markers

tralian $P$. monodon samples were screened with the IHHNV392F/R primers. Of these, 16 samples were observed to elicit a 392 bp band (Fig. 1), indicating the probable presence of IHHNV.

No Penaeus monodon from Australian samples showed positive amplification with any of the other 6 IHHNV-specific PCRs listed in Table 1. However, amplification products of the correct sizes were observed in all these PCRs with P. stylirostris from New Caledonia.

\section{Sequencing}

The 392 bp amplicons produced from Australian Penaeus monodon and New Caledonian P. stylirostris samples using the screening PCR (IHHNV392F/R) were successfully sequenced. This represents just under $10 \%$ of the IHHNV genome. The Australian and New Caledonian sequences were given Accession Nos. AY590120 and AY590121 respectively upon submission to GenBank. BLAST searches of these sequences at the GenBank NCBI database produced significant alignments (E value $<0.05$ ) with previously submitted IHHNV sequences with geographical origins from Madagascar (Accession No. AY125423), Tanzania (AY124937), Thailand (AY102034), Mexico (AF273215) and Hawaii (AF218266) (Fig. 2). The Australian sequence shared the highest nucleotide similarity of $96.2 \%(377 / 392)$ with the Madagascan IHHNV strain, followed by $91.3 \%$ (358/392) similarity with the 
Tanzanian strain, 91.1\% (357/392) similarity with the strain from Thailand, 90.3\% (354/392) similarity with the New Caledonian sequence, and 90.1\% (353/392) similarity with the strains from Mexico and Hawaii (Fig. 2). The New Caledonian sequence showed the highest nucleotide similarity at $99.7 \%$ (391/392) with the Mexican and Hawaiian strains. Furthermore, the New Caledonian sequence had a similarity of $97.7 \%$ (383/392) with the Thai strain, and 94.6\% (371/392) with the Tanzanian strain. The lowest similarity was $89.5 \%(351 / 392)$ with the Madagascan strain.

\section{DISCUSSION}

The results in this study confirmed that an IHHNV strain has been present amongst Australian penaeid prawns since at least 1993. Sixteen out of 20 prawns were found to be IHHNV positive with the use of IHHNV-specific PCR and the result was confirmed by sequencing the derived PCR products. It was also shown that the majority of published and available primers designed for PCR detection of IHHNV, including those provided by the Office International des Epizooties (OIE 2003b), do not react with the Australian strain of IHHNV. In contrast, all PCRs elicited positive results for the control samples from New Caledonia. In this study, only the IHHNV392F/R primers (Tang \& Lightner 2002), located in the non-structural protein 1 region of the IHHNV genome (Shike et al. 2000), elicited a positive PCR for the Australian prawns.

The IHHNV primers tested in the PCR for these experiments were all designed based on the fully sequenced IHHNV genome from the Hawaiian strain (GenBank AF218266).

High sequence variations, particular in the open reading frame encoding non-structural protein 1 , have been demonstrated amongst the various geographical IHHNV strains in samples of Penaeus monodon. Up to $14 \%$ sequence divergence has been found, the highest between the Hawaii and Madagascar IHHNV isolates (Tang et al. 2003). This contrasted with previous indications that IHHN parvovirus from different geographical regions showed little genetic drift and was highly stable (Nunan et al. 2000, Tang \& Lightner 2002). Investigation of 14 isolates from $P$. stylirostris and P. vannamei from the Americas showed $0.5 \%$ nucleotide divergence in the relative short timeframe from 1982 to 1997.

Interestingly, the Australian IHHNV strain shared the highest nucleotide similarity with the Madagascar IHHNV isolate $(96.2 \%)$ and highest divergence with the Hawaii isolate $(90.1 \%)$. The high nucleotide variation observed between the Australian and Hawaiian strains provide an explanation for the lack of detection of IHHNV amongst Australian prawns with the pub- lished IHHNV PCRs and commercially available probes as they are based on the Hawaiian strain.

The New Caledonian sequence had only one nucleotide change from the Mexican and Hawaiian IHHNV strain and shared a sequence similarity of $99.7 \%$. This correlates to the history of the New Caledonian Penaeus stylirostris, which was derived from a Mexican strain imported and introduced to New Caledonia in 1981 (Mermoud et al. 1998), and suggests that IHHNV might have been concurrently introduced with those prawns. Moribund prawns in culture facilities in New Caledonia have been found to have IHHNV prevalence up to $99 \%$ (94 out of 95). However, the detected levels were apparently fairly low (Costa et al. 1998). New Caledonia is the closest neighbor to Australia with verified IHHNV, yet these 2 isolates showed a nucleotide similarity of only $90.3 \%$, again suggesting that the IHHNV strain found in Australia is not derived from the Americas via New Caledonia.

Epidemiological studies currently conducted on Australian prawns from 1993 to 2003 have shown that prawns from 1993, 1995, 1997, 1999 and 2003 derived from various culture facilities in northern Queensland are PCR positive for IHHNV (unpubl. data). Current results suggest that the prevalence of IHHNV amongst Penaeus monodon in Australia is seemingly high, with up to $80 \%$ in samples investigated. The full epidemiological picture is being developed and will be addressed in a subsequent publication.

Often the effect of viral diseases in prawns, particularly chronic non-pathognomic diseases, has been seriously underestimated. IHHNV has been suggested to be the aetiological factor in runt-deformity syndrome (RDS) in Penaeus vannamei (Kalagayan et al. 1991, Browdy et al. 1993) and P. monodon (Primavera \& Quinitio 2000). RDS is a chronic disease that causes deformities and runting in the prawn, leading to decreased growth rates, increased size variations, reduced market value and subsequently significant economical losses of the crop. It is apparent that IHHNV is asymptomatic in the seemingly healthy Australian prawns. However, occasional large size variations and symptoms similar to those for RDS have been observed amongst Australian cultured prawn populations (Young 1997). No morphological deformities were examined in this current study.

Australia has been considered to be relatively disease-free due to its geographical seclusion and strict quarantine policies. However, the marine environment and fauna are part of the Indo-Pacific region and as a consequence analogous pathogens will be expected to occur there as well. The natural geographic range of IHHNV is within the region of Southeast Asia and Penaeus monodon is its main host species (Lightner 1996). This factor and the evidence provided in this 
and previous studies (Owens \& Hall-Mendelin 1990, Owens et al. 1992) suggest that the strain of IHHNV found in penaeid prawn in Australia is endemic and it has been present over a long geological timeframe. Indeed, IHHNV appears to have at least 2 lineages. The old (geological time frame) IHHNV represented by Australian and Madagascan strains and the contemporarily dispersed $P$. stylirostris strain originally from the $P$. monodon from the Philippines, represented by the Hawaiian, Mexican, Thai, and New Caledonian strains. Further comparative work is required to fully elucidate the relatedness of the various IHHNV strains from different geographical areas.

\section{LITERATURE CITED}

Bonami JR, Trumper B, Mari J, Brehelin M, Lightner DV (1990) Purification and characterisation of infectious hypodermal and haematopoietic necrosis virus of shrimps. J Gen Virol 71:2657-2664

Browdy CL, Holloway JD, King CO, Stokes AD, Hopkins JS, Sandifer PA (1993) IHHN virus and intensive culture of Penaeus vannamei: effects of stocking density and water exchange. J Crustac Biol 13:87-94

Costa R, Mermoud I, Mari J, Bonami JR, Hasson K, Lightner DV (1998) Investigations on a disease of Penaeus stylirostris ('Syndrome 93') in New Caledonia, exploring a viral hypothesis. Aquaculture 164:311-322

Fraser C, Owens L (1996) Spawner-isolated mortality virus from Australian Penaeus monodon. Dis Aquat Org 27:141-148

Kalagayan H, Godin D, Kanna R, Hagino G, Sweeney J, Wyban J (1991) IHHN virus as an etiological factor in Runt-Deformity Syndrome (RDS) of juvenile Penaeus vannamei cultured in Hawaii. J World Aquacult Soc 22(4): 235-243

Lightner DV (1996) The penaeid shrimp viruses IHHNV and TSV: epizootiology, production impacts and role of international trade in their distribution in the Americas. Rev Sci Tech Off Int Epizoot 15:579-601

Lo CF, Leu JH, Ho CH, Chen CH and 8 others (1996) Detection of baculovirus associated with white spot syndrome (WSBV) in penaeid shrimps using polymerase chain reaction. Dis Aquat Org 25:133-141

Mermoud I, Costa R, Ferre O, Goarant C, Haffner P (1998)

Editorial responsibility: Timothy Flegel,

Bangkok, Thailand
'Syndrome 93' in New Caledonian outdoor rearing ponds of Penaeus stylirostris: history and description of 3 major outbreaks. Aquaculture 164:323-335

Nunan LM, Poulos BT, Lightner DV (2000) Use of polymerase chain reaction for the detection of infectious hypodermal and hematopoietic necrosis virus in penaeid shrimp. Mar Biotechnol 2:319-328

OIE (2000) Diagnostic Manual for Aquatic Animal Diseases, 2000 3rd edn. Office International des Epizooties, Paris

OIE (2003a) Aquatic Animal Health Code, 2003 6th edn. Office International des Epizooties, Paris

OIE (2003b) Manual of Diagnostic Tests for Aquatic Animals, 2003 4th edn. Office International des Epizooties, Paris

Owens L (1987) First Australian Prawn Farming Research Workshop, Salamander Bay NSW. NSW Department of Agriculture, Salamander Bay

Owens L, Hall-Mendelin S (1990) Recent advances in Australian penaeid diseases and pathology. Advances in Tropical Aquaculture, Tahiti (1989). Actes Colloq 9:103-112

Owens L, Anderson IG, Kenway M, Trott L, Benzie JAH (1992) Infectious hypodermal and haematopoietic necrosis virus (IHHNV) in an interspecies hybrid penaeid prawn from tropical Australia. Dis Aquat Org 14:219-278

Primavera JH, Quinitio ET (2000) Runt-deformity syndrome in cultures giant tiger prawn Penaeus monodon. J Crustac Biol 20:796-802

Shike H, Dhar AK, Burns JC, Shimizu C, Jousset FX, Klimple KR, Bergoin M (2000) Infectious hypodermal and hematopoietic necrosis virus of shrimp related to mosquito brevidensoviruses. Virology 277:167-177

Tang KFJ, Lightner DV (2002) Low sequence variation among isolates of infectious hypodermal and hematopoietic necrosis virus (IHHNV) originating from Hawaii and the Americas. Dis Aquat Org 49:93-97

Tang KFJ, Durand SV, White BL, Redman RM, Pantoja CR, Lightner DV (2000) Postlarvae and juveniles of a selected line of Penaeus stylirostris are resistant to infectious hypodermal and hematopoietic necrosis virus infection. Aquaculture 190:203-210

Tang KFJ, Poulos BT, Wang J, Redman RM, Shih H, Lightner DV (2003) Geographic variation among infectious hypodermal and hematopoietic necrosis virus (IHHNV) isolates and characteristics of their infection. Dis Aquat Org 53: 91-99

Young ND (1997) A histopathological survey investigating a new disease syndrome in the giant tiger prawn (Penaeus monodon) in north Queensland, Australia. BSc (Hons) thesis, James Cook University, Townsville

Submitted: November 12, 2003; Accepted: May 9, 2004 Proofs received from author(s): September 7, 2004 